\title{
Deficiencies in Nutritional Intake in Patients with Diabetic Foot Ulcers
}

\author{
Haiyan M. Maier*, Jasminka llich-Ernst, Bahram Arjmandi, Jeong-Su Kim and \\ Maria T. Spicer
}

\author{
Department of Nutrition, Food, and Exercise Sciences, College of Human Science, The Florida State \\ University, Tallahassee, FL, USA
}

\begin{abstract}
Aims: This study examined the dietary and anthropometric components of diabetic patients with or without diabetic foot ulcers (DFU).

Methods: Eighty-two adult subjects were recruited in Tallahassee, FL (USA) and categorized into one of three groups: subjects without diabetes, patients with Diabetes Mellitus (DM) but not foot ulcers, and patients with DFU. Twenty-four hour food recalls, foot ulcer history and blood samples were collected from each subject. Dietary intake was evaluated with Food Processor. Biomarkers of inflammation and oxidative stress were measured with ELISA kits.

Results: DFU subjects in this study were mostly overweight or obese. DFU had inadequate intakes in protein, fiber, vitamin B1, B2, B3, B6, C, D, and E; calcium, magnesium, phosphorus, potassium, selenium, and zinc. They had excessive intakes in saturated fat, trans fat, and sodium.

Conclusions: Malnutrition is very common in the DM and DFU subjects. Protein and vitamin supplementation may be
\end{abstract} beneficial in prevention and management of DM as well as DFU.

Keywords: Diabetes, Diabetic Foot, Wounds, Nutrition, Malnutrition, Protein.

\section{INTRODUCTION}

Diabetic foot ulcers (DFU) affect $12 \%$ of patients with Diabetes Mellitus (DM) in the United States (U.S.), which if not properly treated or managed leads to lifethreatening consequences, such as lower limb amputation [1]. Despite educational and preventive efforts to decrease the incidence of DFU and lower limb amputations, the rates of both have actually increased [2]. The severity of amputation increases morbidity and mortality as well as costs associated with medical care, rehabilitation and loss of productivity [3]. With the aging of the population and the increasing prevalence of diabetes $(9.3 \%, 2014)$, amputation rates and associated costs may increase further [2].

It is well know that diabetes mellitus patients have compromised wound healing with an average healing time of 10-11 weeks [4]. However, conservative and local treatments often fail, leaving patients with nonhealing chronic wounds or amputations [5]. DFU are chronic wounds which have failed to proceed in an orderly and timely reparative process within 8 weeks, which is responsible for $50-70 \%$ of all non-traumatic amputation [6]. Despite the many advanced technologies that have been developed, such as cultured human dermis transplantation (Dermagraft),

*Address correspondence to this author at the Department of Nutrition, Food, and Exercise Sciences, The Florida State University, Tallahassee, FL 32306, USA; Tel: 1-850-645-7169; Fax: 1-850-644-5000; E-mail: hmaier@fsu.edu epidermal cells (Apligraf), recombinant human PDGF (rhPDGF), and Hyperbaric Oxygen (HBO) therapy [79], nutritional intervention has not been considered as a possible adjunctive or complimentary treatment for DFU.

Normal cutaneous wound healing usually follows a well-orchestrated integration of complex biological and molecular events including coagulation, inflammation, cell migration and proliferation, and tissue remodeling [10]. Proper nutrition is fundamental to support a healthy immune system and promote cell proliferation and protein synthesis involved in the healing process [11]. Overall nutrition status and individual nutrients, such as fatty acids (e.g. omega 3 ), protein, iron, zinc, and anti-oxidative vitamins (vitamin $\mathrm{A}, \mathrm{C}$, and $\mathrm{E}$ ), have been proven to be beneficial in wound healing [12-15].

Investigations using animal and human models have shown that vitamins and minerals play essential role in glucose metabolism therefore they are important in the prognosis and management of DM. It is recommended that daily vitamins and minerals consumption from natural and modified food sources would be beneficial in decreasing the risk of DM as well as its complications [16].

Only two studies, none in the U.S., have evaluated dietary patterns and intake of specific nutrients in patients with DFU. In a French study, DFU patients had significantly lower vitamin $E$ intake $(9.4$ v.s.12.5 $\mathrm{mg} /$ day) and higher alcohol consumption (27.2 v.s.6.7 
g/day) than patients with diabetes but without DFU [17]. Results from an Indian study showed that DFU patients with non-healing wounds had significantly lower vitamin C intake and serum protein compared to healthy controls [4]. Dietary pattern and food choices are highly affected by culture. This has not been explored in the U.S. especially with regard to DFU.

The objective of this study is to compare nutrient intake and anthropometric data of patients with diabetes and with or without DFU in order to identify dietary risk factors for the occurrence for DFU.

\section{METHODS}

\section{Study Design}

The Human Subjects Committee of The Florida State University (FSU) and Institutional Review Board of Capital Regional Medical Center (CRMC) and Tallahassee Memorial Healthcare (TMH) in Tallahassee, Florida, U.S., approved the research protocols. A total of 82 subjects were recruited from the CRMC and $\mathrm{TMH}$ wound care facilities, the TMH diabetes center, and the FSU. There were three distinctly different groups in the present study in reference to their health status as follows: 1) control group (Control; $\mathrm{n}=26$ ) with an average age of $55.7 \pm 7.1$ years; 2 ) individuals with controlled type 2 diabetes but without foot ulcer (DM; $n=26$ with an average age of $60.5 \pm$ 7.8 years; and 3) patients with diabetic foot ulcers (DFU; $n=30$ ) with an average age of $61.17 \pm 9.1$ years. Subjects' characteristics are present in Table 1. Sample size estimation was determined as a function of effect size (ES), the significance criterion (alpha) and the statistical power. With significance accepted a priori at $p<0.05$ and with the accepted ES of 0.80 , a minimum of 26 subjects in each group were required [18].

Written informed consent was obtained from all subjects prior to data collection. One 24-hour food recall was collected at the initial interview. Two other 24-hour food recalls were collected by phone on two different days of the week in the following four weeks after the initial interview. Control subjects were defined as generally healthy individuals, without diabetes, without direct family members with diabetes, and not taking more than one prescription medication. Subjects in group DM and DFU must have been previously diagnosed with diabetes by a medical doctor. Subjects in DM group were in good glucose control according to self-reported Hemoglobin A1C of less than $7.5 \%$ and free of severe diabetic complications such as nephropathy, retinopathy, and neuropathy. Inclusion criteria for the DFU group were diagnosis of DFU and without severe diseases, such as end-stage renal diseases, organ transplants or cancer.

\section{Dietary Assessment}

Dietary intake was estimated from the average of three 24-hour food records of two weekdays and one weekend day. Nutrient intake and percentage nutrients consumption based on dietary reference intakes (DRIs) were estimated using Food Processor SQL 10.1.0 (ESHA Research, Salem, OR). Nutrients intake are presented in absence of dietary supplements. Nutrients included in the analysis were total energy, fat, protein, carbohydrate, dietary fiber, vitamins, and minerals, percent of energy from fat, protein, and carbohydrate. The servings of fruits and vegetables were manually estimated based on Choose Your Foods: Exchange Lists for Diabetes [19].

\section{Biochemical Analyses}

Non-fasting serum sample were collected from all participants. Markers of inflammation and oxidative stress were measured using the serum samples. Creactive protein (CRP) was measured using CRP high sensitive enzyme-linked immunosorbent assay (ELISA) commercial kits (IBL international, Hamburg, Germany). Lipid peroxides (LPO) were measured using thiobarbituric acid reactive substances (TBARS) assay kits (R\&D Systems, Inc. Minneapolis, MN).

\section{Statistical Analyses}

Data was analyzed using the Statistical Package for Social Science (SPSS) version 21.0 (SPSS, Inc., Chicago, IL). All variables were normally distributed. Results were presented as mean \pm standard deviation. The designated statistical significance value was $p<$ 0.05 for all tests. Descriptive statistics and comparative one way ANOVA were conducted to provide population characteristics and to determine differences among groups with post hoc Bonferroni's correction for multiple comparisons. Correlation analyses were evaluated by Pearson's correlation coefficient. General linear model was established to predict the duration of DFU using the best predictors gleaned from Pearson's correlations and ANOVA.

\section{RESULTS}

\section{General Characteristics (Table 1)}

The mean age of the study population was 59 years old. The subjects with diabetes (DM and DFU) were 
Table 1: General Characteristics of the Study Population

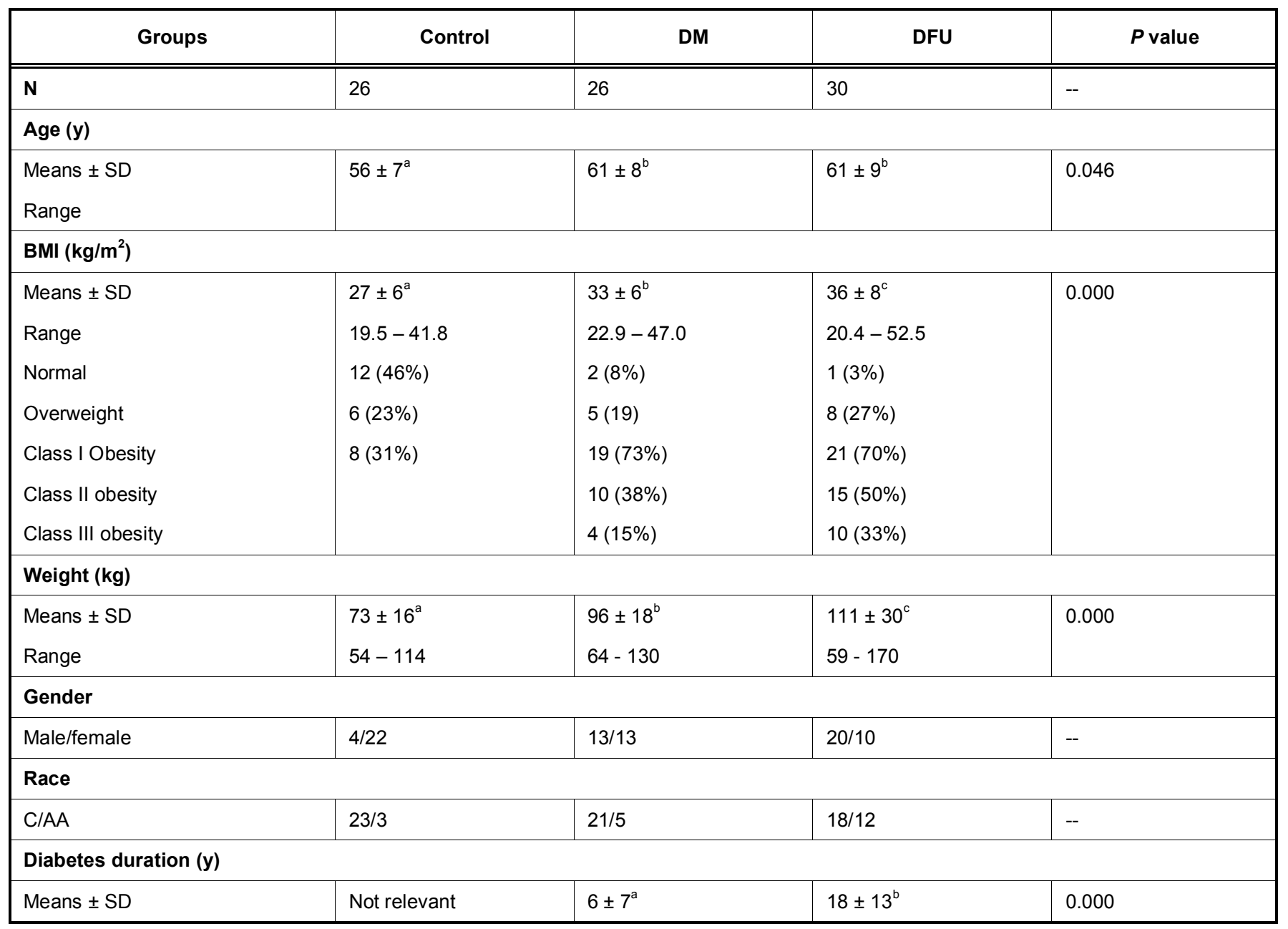

Note: Results are presented as mean \pm SD. Different symbols $\left({ }^{a},{ }^{b},{ }^{c}\right)$ show differences between groups $(p<0.05)$. One-way ANOVA used for differences among groups with post hoc Bonferroni's correction for multiple comparisons. BMI, body mass index; C, control subjects without diabetes; DM, patients with diabetes but without DFU; DFU, subjects with DFU.

older than the control group in average $(p<0.05)$. However, there was no age difference between DM and DFU. The BMI of DFU and DM were $36 \pm 8$ (mean \pm S.D.) and $33 \pm 6$, respectively, which was significantly greater than control $(27 \pm 6)$. Only one of the 30 DFU patients and two of the 26 DM subjects had a BMI < 25 . Seventy-three percent of subjects of the DM group and $70 \%$ of the DFU were obese (BMI > 30). Body weight was significantly different among the three groups $(p<0.001)$. DFU $(111 \pm 30 \mathrm{~kg})$ had significant higher body weight compared with DM $(96 \pm 18 \mathrm{~kg}, p=$ $0.028)$, which was greater than control $(73 \pm 16 \mathrm{~kg})$. The male/female ratio of the control, in control, DM and DFU groups were 4/22, 13/13 and 20/10, respectively. There were no gender differences in all analyzed parameters. Mean duration of diabetes mellitus in the DFU group (18 $\pm 13 \mathrm{yr})$ was significantly longer than mean duration of diabetes in the DM group $(6 \pm 7 \mathrm{yr}, p$ $=0.000$ ).

\section{Energy and Macronutrients (Table 2)}

Energy intake was below $90 \%$ of the Dietary Reference Intakes for Americans (DRI) in all subjects. However, DM and control group having more than $80 \%$ of the DRI, while DFU only met an average of $55 \%$ of DRI for energy. Estimated protein consumption of the DFU subjects $(0.57 \mathrm{~g} / \mathrm{kg})$ were below the recommended protein intakes for adults. This was significantly lower than the DM $(0.97 \mathrm{~g} / \mathrm{kg})$ and control $(1.02 \mathrm{~g} / \mathrm{kg})$ groups, which met the protein recommendations $(0.8 \mathrm{~g} / \mathrm{kg})$.

For all groups, energy from total fat accounted for approximately $30-35 \%$ of total energy and intake of saturated fat was about $10 \%$ of total energy. There were significantly differences among the groups for trans-fat intake with DM having the highest $(3.23 \mathrm{~g})$ and control having the lowest $(0.68 \mathrm{~g})$. DFU $(255 \mathrm{mg})$ and control $(235 \mathrm{mg})$ had average cholesterol intakes below 
Table 2: Dietary Intakes of Macronutrients

\begin{tabular}{|c|c|c|c|c|}
\hline Parameters & Control & DM & DFU & $p$ value \\
\hline Total energy, Kcal & $1654 \pm 510$ & $1913 \pm 799^{a}$ & $1394 \pm 432^{b}$ & 0.008 \\
\hline Total fat, $\mathrm{g}$ & $61.2 \pm 29.6$ & $73.7 \pm 39.4$ & $54.5 \pm 25.0$ & 0.089 \\
\hline Perct. cal, \% & $32.5 \pm 9.8$ & $34.3 \pm 9.9$ & $34.9 \pm 9.0$ & 0.606 \\
\hline Sat. fat, $g$ & $17.9 \pm 8.3$ & $21.5 \pm 12.3$ & $16.7 \pm 8.3$ & 0.198 \\
\hline Perct. cal, \% & $9.5 \pm 3.5$ & $9.9 \pm 3.3$ & $10.9 \pm 3.9$ & 0.355 \\
\hline Trans fat, $\mathrm{g}$ & $0.68 \pm 1.02^{a}$ & $3.23 \pm 4.71^{b}$ & $1.25 \pm 1.48$ & 0.016 \\
\hline Perct. cal, \% & $0.4 \pm 0.8$ & $1.5 \pm 2.3$ & $0.8 \pm 1.1$ & \\
\hline Cholesterol, mg & $235 \pm 176$ & $317 \pm 220$ & $255 \pm 151$ & 0.270 \\
\hline Total protein, $\mathrm{g}$ & $72 \pm 25$ & $90 \pm 39^{a}$ & $60 \pm 27^{b}$ & 0.003 \\
\hline Protein per $\mathrm{kg}$ & $1.02 \pm 0.39^{\mathrm{a}}$ & $0.97 \pm 0.45^{\mathrm{a}}$ & $0.57 \pm 0.27^{b}$ & 0.000 \\
\hline \multicolumn{5}{|l|}{ Food groups } \\
\hline Vegetables, serv. & $1.7 \pm 1.3$ & $2.0 \pm 1.6^{a}$ & $0.9 \pm 0.9^{b}$ & 0.005 \\
\hline Fruits, serv. & $1.2 \pm 0.9$ & $1.2 \pm 1.2$ & $1.1 \pm 1.1$ & 0.606 \\
\hline Dietary fiber, $\mathrm{g}$ & $19.1 \pm 7.0$ & $25.0 \pm 20.8^{a}$ & $11.9 \pm 4.8^{b}$ & 0.001 \\
\hline
\end{tabular}

Note: Results are presented as mean \pm SD. Different symbols $\left({ }^{a},{ }^{b}\right)$ show differences between groups $(p<0.05)$. One-way ANOVA used for differences among groups with post hoc Bonferroni's correction for multiple comparisons. AGE, advanced Glycation end products; CRP, C-reactive protein; TNF- $\alpha$, Tumor necrosis factor-alpha; TBARS, thiobarbituric acid reactive substances; C, control subjects without diabetes; DM, participants with diabetes mellitus but without foot ulcers; DFU, participants with DFU.

Table 3: Dietary Intakes of Micronutrients

\begin{tabular}{|c|c|c|c|c|c|c|c|c|}
\hline & \multicolumn{4}{|c|}{ Actual Intake } & \multicolumn{4}{|c|}{ Intake as a percentage of RDA/AI (\%) } \\
\hline & Control & DM & DFU & $p$ & Control & DM & DFU & $p$ \\
\hline Vitamin A, $\mu \mathrm{g}$ & $415 \pm 285$ & $413 \pm 521$ & $300 \pm 284$ & 0.320 & $50 \pm 15$ & $51 \pm 48$ & $36 \pm 32$ & 0.129 \\
\hline Thiamin, mg & $1.24 \pm 0.33$ & $1.00 \pm 0.75$ & $0.79 \pm 0.45$ & 0.304 & $122 \pm 59$ & $88 \pm 47$ & $66 \pm 27$ & 0.026 \\
\hline Riboflavin, mg & $1.59 \pm 1.56$ & $1.26 \pm 0.72$ & $1.08 \pm 0.65$ & 0.213 & $138 \pm 48$ & $109 \pm 42$ & $91 \pm 40$ & 0.082 \\
\hline Niacin, mg & $14 \pm 7$ & $14 \pm 10$ & $12 \pm 8$ & 0.648 & $163 \pm 48^{\mathrm{a}}$ & $140 \pm 57^{a}$ & $77 \pm 44^{\mathrm{b}}$ & 0.040 \\
\hline Vitamin $\mathrm{B} 6, \mathrm{mg}$ & $1.57 \pm 1.83$ & $1.25 \pm 0.75$ & $0.85 \pm 0.48$ & 0.077 & $119 \pm 73$ & $80 \pm 50$ & $53 \pm 27$ & 0.010 \\
\hline Vitamin B12, $\mu \mathrm{g}$ & $6.11 \pm 10.87$ & $2.68 \pm 2.55$ & $3.30 \pm 6.22$ & 0.243 & $108 \pm 64$ & $113 \pm 72$ & $98 \pm 51$ & 0.216 \\
\hline Vitamin C, mg & $84 \pm 71$ & $71 \pm 59$ & $55 \pm 44$ & 0.194 & $122 \pm 41$ & $84 \pm 62$ & $60 \pm 30$ & 0.097 \\
\hline Vitamin D, IU & $82 \pm 99$ & $66 \pm 61$ & $76 \pm 72$ & 0.812 & $14 \pm 11$ & $10 \pm 4$ & $13 \pm 9$ & 0.648 \\
\hline Vitamin $\mathrm{E}, \mathrm{mg}$ & $9.53 \pm 17.73$ & $5.04 \pm 4.61$ & $3.43 \pm 3.24$ & 0.102 & $60 \pm 56^{b}$ & $32 \pm 29^{a}$ & $22 \pm 22^{a}$ & 0.012 \\
\hline Calcium, mg & $660 \pm 288^{a}$ & $615 \pm 323$ & $451 \pm 199^{b}$ & 0.014 & $64 \pm 20^{\mathrm{a}}$ & $56 \pm 29^{a}$ & $42 \pm 17^{b}$ & 0.013 \\
\hline Magnesium, mg & $205 \pm 151$ & $239 \pm 188^{a}$ & $136 \pm 87^{b}$ & 0.034 & $67 \pm 33^{a}$ & $64 \pm 30^{a}$ & $38 \pm 13^{b}$ & 0.026 \\
\hline Iron, mg & $11.34 \pm 4.24$ & $13.43 \pm 7.30^{a}$ & $9.33 \pm 4.27^{b}$ & 0.026 & $162 \pm 47^{\mathrm{a}}$ & $167 \pm 59^{a}$ & $113 \pm 44^{\mathrm{b}}$ & 0.039 \\
\hline Phosphorus, mg & $729 \pm 355$ & $1027 \pm 1257$ & $593 \pm 324$ & 0.113 & $127 \pm 32$ & $140 \pm 74$ & $85 \pm 39$ & 0.148 \\
\hline Potassium, $\mathrm{g}$ & $1.70 \pm 0.56^{a}$ & $3.04 \pm 3.22^{b}$ & $1.48 \pm 0.75^{a}$ & 0.008 & $42 \pm 11^{a}$ & $65 \pm 49^{b}$ & $33 \pm 8^{a}$ & 0.004 \\
\hline Selenium, mcg & $63 \pm 49$ & $55 \pm 34$ & $49 \pm 50$ & 0.547 & $141 \pm 59$ & $107 \pm 50$ & $84 \pm 49$ & 0.068 \\
\hline Sodium, mg & $2690 \pm 820$ & $4200 \pm 3560$ & $3040 \pm 2200$ & 0.080 & $244 \pm 52^{a}$ & $323 \pm 110^{b}$ & $235 \pm 162^{a}$ & 0.008 \\
\hline Zinc, mg & $6.59 \pm 3.95$ & $6.05 \pm 3.99$ & $6.14 \pm 6.36$ & 0.919 & $96 \pm 40$ & $64 \pm 38$ & $68 \pm 60$ & 0.164 \\
\hline
\end{tabular}

Note: Different symbols $\left({ }^{a},{ }^{b},{ }^{c}\right)$ show differences between groups $(p<0.05)$. One-way ANOVA used for differences among groups with post hoc Bonferroni's correction for multiple comparisons. C: Control, subjects without diabetes; DM, patients with diabetes but without DFU; DFU, subjects with DFU.

the recommendation of $300 \mathrm{mg}$; while the subjects in DM group consumed in average $317 \mathrm{mg}$ cholesterol per day.

Total sugar intake did not differ among the three groups while fiber intake was the highest in the DM (25g) and lowest in the DFU (11.9g). All participants consumed less than $75 \%$ of recommended of amount for fiber, with DFU only consume $35 \%$ of the DRI for fiber. None of the groups met the dietary recommendation of consuming at least three servings of vegetables and two servings of fruits daily, DFU had 
the lowest vegetable intake compared with $D M$ and control with less than one servings per day $(p=0.002)$.

\section{Micronutrients (Table 3)}

Since the study population has compromised fruits and vegetable intake overall, inadequate intakes of almost all micronutrients have been observed, particularly in DFU group. Using the RDA or Al for the age group as reference for adequacy, all groups had extremely low intakes of vitamin $\mathrm{D}(\sim 12 \%)$ and $\mathrm{E}$ $(\sim 38 \%)$ while all had adequate intakes of iron and sodium. Of the nine vitamins studied, no statistical differences were detected among the three groups in the intakes of vitamin A, B12, C, D, and riboflavin. Most alarmingly, all participants had less than $20 \%$ of RDA for vitamin $D$ from their diet. All groups had diet deficient in calcium, magnesium, and potassium regardless of existence of diabetes mellitus while the intakes of iron and sodium were above $100 \%$ of RDA. Sodium intake was extremely high with DM consuming more than $300 \%$ adequate intake (AI) for sodium; $4200 \mathrm{~g} /$ day in average. DFU had significantly lower intake in calcium $(p=0.013)$, magnesium $(p=0.026)$, iron $(p=0.039)$, and potassium $(p=0.004)$ compared with DM and control.

\section{The Association between Nutrients and Markers of Inflammation}

The associations of biochemical findings and wound healing have been reported elsewhere [20]. The intakes of fruits and vegetables also inversely associated with TBARS (Figure 1). There was a strong negative correlation between CRP and dietary vitamin $C(r=0.341, p=0.021)$ (Figure 2). This indicated the reverse association of the levels of anti-oxidative vitamins and inflammation in the body.

\section{DISCUSSION}

Nutrition is crucial for wound healing. In the current study, subjects with DFU were at high risk for malnutrition as evidenced by significantly low intakes of energy, protein, dietary fiber, vitamin $C, D$, and $E$, calcium, magnesium, iron, and potassium. In addition, the DFU group had the lowest energy intake among the three groups, yet their body weight was the heaviest. Obesity despite very low nutrient intakes may have been due to significantly reduced energy expenditure as a result of physical inactivity, decreased fat-free mass and lowered metabolic rate associated with ageing [21]. The overall morbidity of having a foot ulcer may have contributed to decreased appetite and subsequent reduced energy intake.

Adequate protein intake is essential for the integrity of connective tissue, muscle, and skin. Protein requirements are influenced by disease states, immune status and injuries [11]. In wound healing, large amount of protein is essential for immunological defense and tissue reconstruction [13]. Up to $1.5 \mathrm{~g}$ dietary protein per kg body weight is recommended for chronic wound healing [22]. The DFU subjects in this study had the protein intake of $0.57 \mathrm{~g}$ per $\mathrm{kg}$ well below the RDA of $0.8 \mathrm{~g}$ per $\mathrm{kg}$ per day for healthy adults and only $33 \%$ of the amount recommended for wound healing.

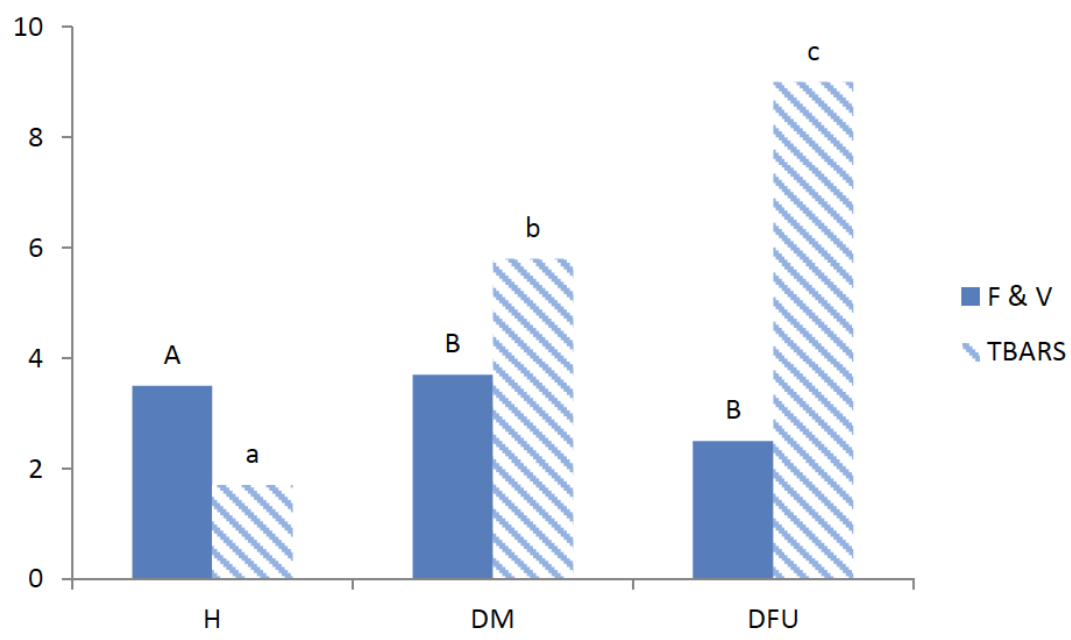

Figure 1: TBARS and the Fruits and Vegetables Intakes.

Dietary intakes of fruits and vegetables were estimated based on 3-day food recalls as described, and data are expressed as servings per day. F \&V, dietary intakes of the combination of fruits and vegetables; TBARS, thiobarbituric acid reactive substances. C: Control, subjects without diabetes; DM, patients with diabetes but without DFU; DFU, subjects with DFU. 


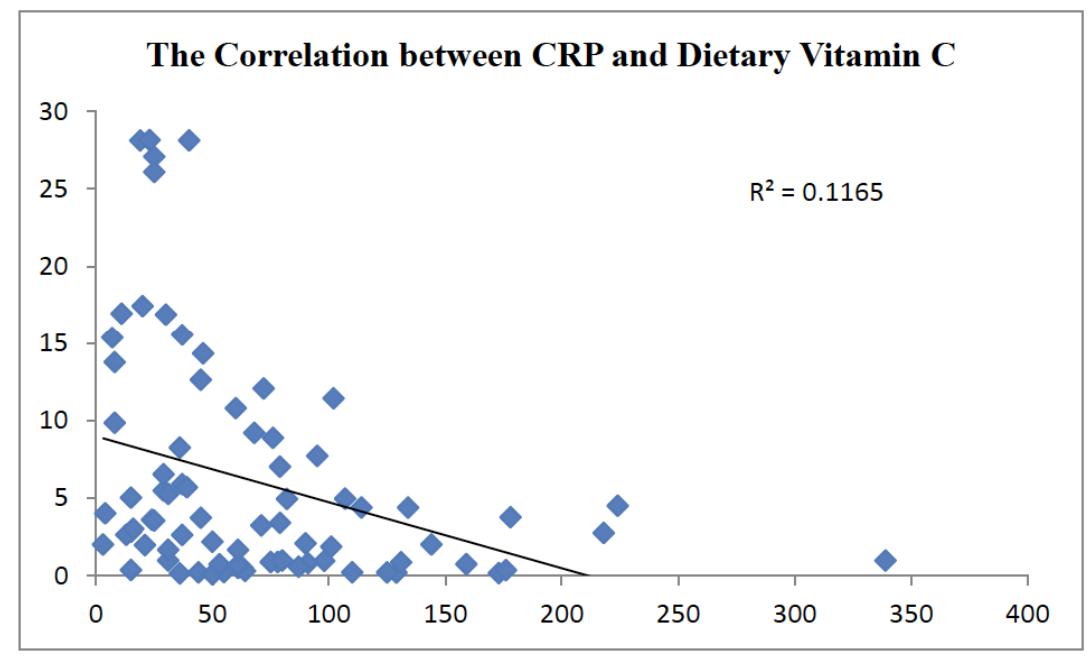

Figure 2: The correlation between CRP and dietary vitamin C.

Dietary intake of vitamin $\mathrm{C}$ was estimated based on 3-day food recalls as described. Data are shown as linear correlations. CRP: C-reactive protein.

In this study, patients with DFU had the lowest intakes of fruits and vegetables and significantly higher levels of oxidative stress and inflammation. The increased oxidative stress accelerates the development of diabetic complications [16]. Many fruits and vegetables are high in vitamins, minerals, and plant polyphenols, which are known to be potent antioxidants. Prospective data analyzed from the Women's Healthy Study showed that dietary intakes of fruits and vegetables were inversely associated with diabetes risk in overweight women [23]. More specifically, the consumption of green leafy vegetables and fruits, but not fruit juices was associated with a lower risk of diabetes among women [24]. The deficiencies in fruits and vegetable intake of DFU subjects may exacerbate the prognosis of diabetic complications.

Patients with diabetic foot complications have been reported with inadequate intakes of magnesium, calcium, zinc, riboflavin, folate and vitamin $A$ in Australia [25]. In this study, DFU subjects were deficient in thiamin, vitamin B6, C, D and E, calcium, magnesium, potassium, and zinc. DM subjects were deficient in vitamin $D$ and $E$, calcium, magnesium, potassium and zinc. Control subjects were deficient in vitamin $\mathrm{D}$ and $\mathrm{E}$, calcium, magnesium, and potassium. Compare to DM and control, DFU subjects were lacking thiamin B6, and had significantly lower intakes in calcium and magnesium.

Vitamin $\mathrm{C}$ and $\mathrm{E}$ are known antioxidant vitamins. In addition, vitamin $C$ is known as the anti-scurvy vitamin necessary for the vitality of the connective tissue. It has been shown that the levels of vitamin $C$ and $E$ in the system decrease when rats experience cutaneous wounding due to increased levels of free radicals [26]. In this study, there was a strong negative correlation between CRP and dietary vitamin $C$ intake. Experimental ascorbic acid deficiency has been shown to cause bleeding gums, and slow healing of wounds and fractures [13]. DFU patients in this study had significantly lower vitamin $E$ intake than patients with diabetes but without foot ulcer consistent with a French study [17].

Inadequate Vitamin D intake is associated with poor glycemic control in type 2 DM. A meta-analysis that examined the roles of vitamin $D$ and calcium in type 2 DM suggested that since deficiencies were negatively associated with glucose metabolism that supplementation with vitamin $D$ and calcium may decrease the risk of diabetes [27]. Although dietary intake of vitamin $D$ was universally low in all subjects in this study, this is still of greater concern in the DFU and DM subjects since vitamin $D$ has been found to be involved in wound healing through the production of cathelicidin, which is a group of antimicrobial peptides that are essential in the innate immune system [28]. Decreased levels of vitamin $D$ may play a role in the impairment of re-epithelialization [29].

Zinc plays a major role in the biochemical and molecular events of tissue repair, such as in zinc finger transcription factors in mRNA coding for growth factors [30]. Zinc deficiency is also related to elevated oxidative stress in diabetes, which has been proposed as a cause of diabetic complications [31]. Dietary zinc defici- 
ency has been reported in $54.5 \%$ patients with chronic wounds, of which 31 home care patients with pressure ulcer or venous stasis ulcer were evaluated [32].

Of great concern is the high sodium and low potassium intake of all participants in the study. With an average intake of $3040 \mathrm{mg}$ sodium and $1480 \mathrm{mg}$ potassium per day, sodium intakes were significantly higher than RDA $(235 \% \mathrm{Al})$, while potassium intakes were significantly lower $(33 \% \quad \mathrm{Al})$ than the recommendations. The dietary guideline for sodium is $2300 \mathrm{mg}$ and the Al for potassium is $4700 \mathrm{mg}$ per day. Hypertension and resistance to blood pressure therapies are associated with high sodium and low potassium intake [33]. This has greater implications for people with DM since they are at higher risk of cardiovascular diseases. In addition, sodium and potassium, as well as calcium, play fundamental role in the secretion of insulin by pancreatic beta cells. The electrical activity from the flux of potassium and calcium across the cell membrane is necessary for the release of hormones. Lower intake of dietary potassium is associated with the increased risk of diabetes. Data analyzed from the Coronary Artery Risk Development in Young Adults (CARDIA) has shown that lower intake of dietary potassium is associated with increased risk of the incidence of diabetes.

It is necessary to address other nutritional problems revealed in this study, more specifically, nutrition and heart diseases. American Heart Association recommends that energy from fat should be within 20$35 \%$ of total energy intake, and that saturated fat should account for less than 7\% of total energy [34]. In this study, fat intake of DFU subjects was $34.9 \%$ of total energy, with saturated fat at $11 \%$. It is well recognized that patients with diabetes have an increased risk for cardiovascular disease. It is recommended that such individuals lower their total fat intake, especially saturated fat intake [35]. Recommended by American Heart Association, energy from trans-fat should be less than $1 \%$ of total energy and cholesterol intake should be less than $300 \mathrm{mg}$. In this study DM participants had the highest trans-fat intake of $3.23 \mathrm{~g}$ per day, which was $1.5 \%$ of total energy, while DFU had trans-fat intake of $0.8 \%$ of total energy. The estimated average trans-fat intake in the US population analyzed from the 2003-2006 HNANES data was $1.3 \mathrm{~g}$ per person per day [36].

The limitation of the study is that the sample size is small. Due to the nature of the disease, particularly DFU, the recruitment of participants are very challenging. However, with larger sample size, the malnutrition phenomenon among these patients would be more significant. From this pilot study, the findings concluded that the DFU subjects in this study definitely require nutrition education and supplementation in order to improve their nutritional status and promote wound healing. If the study sample is representative of the total population of people with DFU, then this has major implications on health care. Nutrition education and promoting supplementation is essential in reducing the cost of wound care as well as wound related morbidity. This prospective study has provided valuable information regarding the nutritional intake of patients with DFU. The DFU subjects in this study had very poor quality nutrition. These findings support the concept that nutritional quality promotes optimal wellness and prevention of morbidity. However, the comorbidity of the study subjects were not considered. It has been noticed that most of the subjects in DFU group were suffering from chronic kidney disorders, which may play a role in their biochemical marker and nutritional intakes. A future research on improving nutritional intake of malnutrition patients with diabetes mellitus may be beneficial in managing diabetes, as well as in preventing diabetic complications, such as DFU.

\section{REFERENCES}

[1] CDC. National Diabetes Fact Sheet 2011.

[2] Bloomgarden ZT. American Diabetes Association 60th Scientific Sessions, 2000: the diabetic foot. Diabetes Care 2001; 24(5): 946-51.

https://doi.org/10.2337/diacare.24.5.946

[3] Moss SE, Klein R, Klein BEK. Long-term incidence of lowerextremity amputations in a diabetic population. Archives of Family Medicine 1996; 5(7): 391-8. https://doi.org/10.1001/archfami.5.7.391

[4] Agrawal S, Pandey SS, Shukla VK, Kaur P. Nutritional and vitamin status of non-healing wounds in patients attending a tertiary hospital in India. J Dermatol 2003; 30(2): 98-103. https://doi.org/10.1111/j.1346-8138.2003.tb00355.x

[5] Wong MW, Leung PC, Wong WC. Limb salvage in extensive diabetic foot ulceration-a preliminary clinical study using simple debridement and herbal drinks. Hong Kong Med $J$ 2001; 7(4): 403-7.

[6] Moulik PK, Mtonga R, Gill GV. Amputation and mortality in new-onset diabetic foot ulcers stratified by etiology. Diabetes Care 2003; 26(2): 491-4. https://doi.org/10.2337/diacare.26.2.491

[7] Chadwick $\mathrm{P}$, Acton $\mathrm{C}$. The use of amelogenin protein in the treatment of hard-to-heal wounds. Br J Nurs 2009; 18(6): S22, S4, S6, passim.

[8] Eldor R, Raz I, Ben Yehuda A, Boulton AJ. New and experimental approaches to treatment of diabetic foot ulcers: a comprehensive review of emerging treatment strategies. Diabet Med 2004; 21(11): 1161-73. https://doi.org/10.1111/j.1464-5491.2004.01358.x

[9] Steed DL, Webster MW, Ricotta JJ, Luterman A, Brown S, Comerota $\mathrm{AJ}$, et al. Clinical-Evaluation of Recombinant 
Human Platelet-Derived Growth-Factor for the Treatment of Lower-Extremity Diabetic Ulcers. Journal of Vascular Surgery 1995; 21(1): 71-81. https://doi.org/10.1016/S0741-5214(95)70245-8

[10] Falanga V. Wound healing and its impairment in the diabetic foot. Lancet 2005; 366(9498): 1736-43. https://doi.org/10.1016/S0140-6736(05)67700-8

[11] Cartwright MM. The metabolic response to stress: a case of complex nutrition support management. Crit Care Nurs Clin North Am 2004; 16(4): 467-87.

https://doi.org/10.1016/S0899-5885(04)00070-X

[12] Shepherd AA. Nutrition for optimum wound healing. Nurs Stand 2003; 18(6): 55-8.

[13] MacKay D, Miller AL. Nutritional support for wound healing. Altern Med Rev 2003; 8(4): 359-77.

[14] Arnold M, Barbul A. Nutrition and wound healing. Plastic and Reconstructive Surgery 2006; 117(7): 42S-58S. https://doi.org/10.1097/01.prs.0000225432.17501.6c

[15] Brown KL, Phillips TJ. Nutrition and wound healing. Clinics in Dermatology 2010; 28(4): 432-9. https://doi.org/10.1016/j.clindermatol.2010.03.028

[16] Maritim AC, Sanders RA, Watkins JB. Diabetes, oxidative stress, and antioxidants: A review. Journal of Biochemical and Molecular Toxicology 2003; 17(1): 24-38. https://doi.org/10.1002/jbt.10058

[17] Rigalleau V, Barbe M, Garuz F, Baillet-Blanco L, Beauvieux MC, Gin H. Nutritional factors and diabetic foot: a role for vitamin E? Diabet Med 2004; 21(8): 951-2. https://doi.org/10.1111/j.1464-5491.2004.01247.x

[18] Cohen J. Statistical power analysis for the behavioral sciences. second edition ed. Hillsdale, Newy Jersey 1988.

[19] ADA. Choose Your Foods: Exchange Lists for Diabetes. American Diabetes Association and American Dietetic Association 2011.

[20] Maier HM, Ilich JZ, Kim J-S, Levenson CW, Arjmandi BH, Spicer MT. Dietary advanced glycation end-products exacerbate oxidative stress in patients with diabetic foot ulcers. Journal of Diabetes Research and Clinical Metabolism 2014; 3(1).

https://doi.org/10.7243/2050-0866-3-2

[21] Pannemans DL, Westerterp KR. Energy expenditure, physical activity and basal metabolic rate of elderly subjects. Br J Nutr 1995; 73(4): 571-81. https://doi.org/10.1079/BJN19950059

[22] Evans E. Nutritional assessment in chronic wound care. J Wound Ostomy Continence Nurs 2005; 32(5): 317-20. https://doi.org/10.1097/00152192-200509000-00009

[23] Liu S, Serdula M, Janket SJ, Cook NR, Sesso HD, Willett WC, et al. A prospective study of fruit and vegetable intake and the risk of type 2 diabetes in women. Diabetes Care 2004; 27(12): 2993-6.

https://doi.org/10.2337/diacare.27.12.2993

[24] Bazzano LA, Li TY, Joshipura KJ, Hu FB. Intake of fruit, vegetables, and fruit juices and risk of diabetes in women. Diabetes Care 2008; 31(7): 1311-7. https://doi.org/10.2337/dc08-0080
[25] Pitt S, May K, Colman P, Wraight P. Deficiencies in nutritional intake in patients admitted with diabetes-related foot complications. Nutrition \& Dietetics 2007; 64(3): 186-91. https://doi.org/10.1111/j.1747-0080.2007.00096.x

[26] Shukla A, Rasik AM, Patnaik GK. Depletion of reduced glutathione, ascorbic acid, vitamin $\mathrm{E}$ and antioxidant defence enzymes in a healing cutaneous wound. Free Radic Res 1997; 26(2): 93-101. https://doi.org/10.3109/10715769709097788

[27] Pittas AG, Lau J, Hu FB, Dawson-Hughes B. The role of vitamin $D$ and calcium in type 2 diabetes. A systematic review and meta-analysis. J Clin Endocrinol Metab 2007; 92(6): 2017-29. https://doi.org/10.1210/jc.2007-0298

[28] Via M. The malnutrition of obesity: micronutrient deficiencies that promote diabetes. ISRN Endocrinol 2012; 2012: 103472. https://doi.org/10.5402/2012/103472

[29] Schwalfenberg GK. A review of the critical role of vitamin D in the functioning of the immune system and the clinical implications of vitamin $D$ deficiency. Mol Nutr Food Res 2011; 55(1): 96-108.

https://doi.org/10.1002/mnfr.201000174

[30] Lansdown ABG, Mirastschijski U, Stubbs N, Scanlon E, Agren MS. Zinc in wound healing: Theoretical, experimental, and clinical aspects. Wound Repair and Regeneration 2007; 15(1): 2-16.

https://doi.org/10.1111/j.1524-475X.2006.00179.x

[31] Salgueiro MJ, Krebs N, Zubillaga MB, Weill R, Postaire E, Lysionek $\mathrm{AE}$, et al. Zinc and diabetes mellitus: is there a need of zinc supplementation in diabetes mellitus patients? Biol Trace Elem Res 2001; 81(3): 215-28. https://doi.org/10.1385/BTER:81:3:215

[32] Wojcik A, Atkins M, Mager DR. Dietary intake in clients with chronic wounds. Can J Diet Pract Res 2011; 72(2): 77-82. https://doi.org/10.3148/72.2.2011.77

[33] Ekinci El, Cheong KY, Dobson M, Premaratne E, Finch S, Maclsaac RJ, et al. High sodium and low potassium intake in patients with Type 2 diabetes. Diabetic Medicine 2010; 27(12): 1401-8.

https://doi.org/10.1111/j.1464-5491.2010.03111.x

[34] Fats and Oils: AHA Recommendation [database on the Internet] 2011 [cited 1/20/2013].

[35] Sarwar N, Gao P, Seshasai SR, Gobin R, Kaptoge S, Di Angelantonio $\mathrm{E}$, et al. Diabetes mellitus, fasting blood glucose concentration, and risk of vascular disease: a collaborative meta-analysis of 102 prospective studies. Lancet 2010; 375(9733): 2215-22. https://doi.org/10.1016/S0140-6736(10)60484-9

[36] Doell D, Folmer D, Lee H, Honigfort M, Carberry S. Updated estimate of trans fat intake by the US population. Food Addit Contam Part A Chem Anal Control Expo Risk Assess 2012; 29(6): 861-74. https://doi.org/10.1080/19440049.2012.664570

\section{DOl: http://dx.doi.org/10.6000/1929-5634.2016.05.04.1}

(C) 2016 Maier et al.; Licensee Lifescience Global.

This is an open access article licensed under the terms of the Creative Commons Attribution Non-Commercial License (http://creativecommons.org/licenses/by-nc/3.0/) which permits unrestricted, non-commercial use, distribution and reproduction in any medium, provided the work is properly cited. 